\title{
Penerapan Project Based Learning pada Perkuliahan Wirausaha Kreatif di Program Studi Desain Komunikasi Visual
}

\author{
Jayanto Ginon11, Kurnia Setiawan² \\ 1 Universitas Tarumanagara \\ 2 Universitas Tarumanagara
}

\begin{abstract}
ARTICLE INFO
Article History:

Received 8 November 2021

Revised 29 Desember 2021

Accepted 29 Desember 2021

Published 31 Desember 2021

\section{Keywords:}

Project Based Learning;

Wirausaha Kreatif;

DKV.

ABSTRACT

The challenge for the implementation of lectures in the era of the covid 19 pandemic is that learning is done online so that it needs appropriate methods to be able to achieve learning goals. To address this, the team of lecturers in Creative Entrepreneur courses in the Visual Communication Design Study Program (DKV) of the Faculty of Fine Arts and Design, Tarumanagara University chose the Project-Based Learning method for 2020/2021 even semester. The research examines how the application of project-based learning in FSRD Untar creative entrepreneur courses. The research conducted is qualitative descriptive using case study methods through interviews, observations, artifacts, and interpretations. The case study was conducted in the Odd Semester Creative Entrepreneur class 2021/2022 at the Faculty of Fine Arts and Design. This research is participatory research because researchers are involved in lecture activities that will be held. The results of the study describe the implementation of project-based learning carried out in 4 stages: briefing, monitoring, presentation, and evaluation. Motivating students are done in various ways (inspirational figures, getting to know their potential, public lectures, etc.). The monitoring process is carried out through assistance/consultation. Students are invited to share and learn from each other through presentations (creative entrepreneurial seminars). Evaluation is carried out through two activities, namely during seminars and exhibitions of works in the form of canvas model business posters made by students. Project-based learning methods are suitable to be applied in Creative Entrepreneur lectures and make students enthusiastic in following the learning and teaching process.
\end{abstract}

\begin{abstract}
Tantangan untuk penyelenggaraan perkuliahan di era pandemi covid 19 adalah pembelajaran dilakukan secara daring sehingga perlu metode yang sesuai untuk dapat mencapai tujuan pembelajaran. Untuk menyikapi hal tersebut, tim dosen mata kuliah Wirausaha Kreatif di Program Studi Desain Komunikasi Visual (DKV) Fakultas Seni Rupa dan Desain Universitas Tarumanagara memilih metode Project Based Learning untuk perkuliahan semester genap 2020/ 2021. Penelitian mengkaji bagaimana penerapan project based learning pada mata kuliah wirausaha kreatif FSRD Untar. Penelitian yang dilakukan bersifat deskriptif kualitatif dengan menggunakan metode studi kasus melalui wawancara, observasi, artefak dan inteprestasi. Studi kasus dilakukan pada kelas Wirausaha Kreatif semester ganjil 2021/ 2022 di Fakultas Seni Rupa dan Desain. Penelitian ini merupakan participatory research karena peneliti terlibat dalam kegiatan perkuliahan yang akan diselenggarakan. Hasil penelitian menjelaskan penerapan project based learning yang dilaksanakan dalam 4 tahapan: briefing, monitoring, presentasi, dan evaluasi. Untuk memotivasi mahasiswa dilakukan berbagai cara (tokoh inspiratif, mengenal potensi diri, kuliah umum, dll). Proses monitoring dilakukan melalui asistensi/ konsultasi. Mahasiswa diajak untuk berbagi dan saling belajar melalui presentasi (seminar wirausaha kreatif). Evaluasi dilakukan melalui dua kegiatan, yaitu pada saat seminar dan pameran karya berupa poster bisnis model canvas yang dibuat oleh mahasiswa. Metode project based learning cocok untuk diterapkan dalam perkuliahan Wirausaha Kreatif dan membuat mahasiswa antusias dalam mengikuti proses belajar dan mengajar.
\end{abstract}

(C) 2021 The Author(s). Published by Universitas Indraprasta PGRI, Jakarta, Indonesia. This is an open access article under the CC BY license (https://creativecommons.org/licenses/by/4.0/)

\section{Corresponding Author:}

Kurnia Setiawan

Email: kurnias@fsrd.untar.ac.id

How to Cite: Ginon, J, Setiawan, K. (2021). Penerapan project based learning pada perkuliahan wirausaha kreatif di program studi desain komunikasi visual. Sosio e-Kons, 13 (03), 261-269 


\section{PENDAHULUAN}

Suatu negara mampu untuk berkembang secara mandiri apabila jumlah wirausahawan di negara tersebut minimal 2 persen dari total jumlah penduduk. Saat ini, jumlah wirausahawan di Indonesia hanya sebesar 0,24 persen dari jumlah penduduk Indonesia sebesar 238 juta jiwa. Jumlah tersebut lebih rendah jika dibandingkan dengan jumlah wirausaha di beberapa negara luaryang tingkat perekonomiannya lebih tinggi, seperti Amerika Serikat yang memiliki wirausaha sejumlah 4 persen dari total penduduknya, Singapura yang jumlah wirausahanya sebesar 7 persen dari jumlah penduduknya, dan Malaysia yang jumlah wirausahanya mencapai 5 persen dari jumlah penduduknya. (Budiarto, 2012)

Berbagai strategi diterapkan oleh pemerintah untuk meningkatkan jumlah wirausahawan di Indonesia, salah satunya ialah dengan memasukkan mata kuliah Kewirausahaan ke dalam kurikulum pendidikan, khususnya pendidikan di tingkat perguruan tinggi. Adanya mata kuliah Kewirausahaan dimaksudkan untuk menambah wawasan mahasiswa terhadap dunia kewirausahaan serta memotivasi mereka untuk ikut terlibat langsung dalam dunia wirausaha sebagai wirausahawan muda yang tangguh, sehingga mereka dapat ikut berkontribusi dalam meningkatkan perekonomian negara Indonesia.

Pendidikan kewirausahaan atau entrepreneurship semakin digalakkan di perguruan tinggi agar lulusan perguruan tinggi mampu mandiri. Pendidikan kewirausahaan di perguruan tinggi diharapkan bisa menyiapkan mahasiswa untuk berani mandiri, tidak lagi terfokus menjadi pencari kerja. Apalagi data pengangguran terdidik di Indonesia menunjukkan, semakin tinggi pendidikan seseorang, semakin rendah kemandirian dan semangat kewirausahaannya. banyak sekali mahasiswa ketika lulus kuliah mereka hanya ingin menjadi seorang pegawai. Pendidikan kewirausahaan mesti berjalan secara berkesinambungan dan menjadi bagian yang tidak terpisahkan dari seluruh proses pendidikan di perguruan tinggi untuk mempersiapkan lulusan perguruan tinggi yang tidak hanya berorientasi sebagai pencari kerja, tetapi juga sebagai pencipta lapangan kerja. Berdasarkan panduan Merdeka Belajar Kampus Merdeka 2020 (Kemendikbud 2020) yang mengutip riset dari IDN Research Institute tahun 2019, ada 69,1\% milenial di Indonesia yang memiliki minat berwirausaha. Oleh karena itu Kementrian Pendidikan dan Kebudayaan melalui Direktorat Pembelajaran dan Kemahasiswaan, Dikrektorat Jenderal Pendidikan Tinggi melaksanakan Program Kewirausahaan Kampus Merdeka sejak tahun 2020 (Sukino, 2021).

Menurut Peter F. Drucker (1909 - 2005), entrepreneur adalah orang yang menyelidikidan menanggapi perubahan serta mengeksploitasinya sebagai sebuah peluang. Entreprenur diterjemahkan dalam bahasa Indonesia menjadi wirausaha. Berasal dari Bahasa sansekerta 'wira' yang berarti manusia unggul, teladan, berbudi pekerti luhur, berjiwa besar, berani, pahlawan/ pendekar, memiliki keagungan watak, sedangkan 'usaha' adalah melakukan kegiatan usaha. Wirausaha bukan sekedar orang yang memiliki ketrampilan berbisnis, melainkan juga memiliki kepemimpinan pribadi yang tinggi, memiliki daya juang, kesabaran, dan toleransi dalam menghadapi berbagai tantangan (Tyas, 2019).

Peranan utama wirausaha dalam sebuah perusahaan ialah menghasilkan keupayaan bisnis hari ini untuk memenuhi keperluan bisnis masa depan. Tidak ada bisnis yang menjadi besar secara langsung, sebagai contohnya banyak bisnis berkembang mulai dari kecil hingga menjadi besar; Wings Group, Indofood, Garuda Food, Astra Group, Sinar Mas, Ciputra Group, dll. Dari perspektif kewirausahaan (entrepreneurship), perkembangan usaha-usaha diatas dilakukan secara konsisten, pantang menyerah dalam menghadapi situasi sulit, dan penuh determinasi sehingga menghasikan kesuksesan. Faktor pendukung keberhasilan bisnis antara lain kemampuan berinovasi, keberanian mengambil resiko yang terhitung sebelumnya (calculated risk). Menurut Peter Drucker dalam buku Innovation and Entrepeneruship (1985) menuliskan tentang pentingnya inovasi bagi entrepreneur.

"Innovation is the specific tool of entrepreneurs, the means by wich thay exploit change as an opportunity for a different business or a different service. It is capable of being presented as a discipline, capable of being learned, capable of being practiced. Entrepreneus need to search purposefully for sources of innovation, the changes and 
their symtoms that indicate opportujities for succesfull innovation. And they need to know and to apply the principles of succesfull innovation".

Pada tahun 2020 Fakultas Seni Rupa dan Desain memasukan kewirausahaan ke dalam kurikulum operasional program studi Desain Interior dan Desain Komunikasi Visual. Hal ini menjadi sejalan dengan semangat Kampus Merdeka yang berimplikasi pada perubahan kurikulum di berbagai perguruan tinggi di Indonesia. SItuasi dan kondisi global juga menuntut dilakukan perubahan cepat berkenaan dengan situasi pandemi yang berdampak global. Tantangan untuk penyelenggaran perkuliahan di era pandemi covid 19 adalah pembelajaran dilakukan secara daring sehingga perlu metode yang sesuai untuk dapat mencapai tujuan pembelajaran. Untuk menyikapi hal tersebut, tim dosen mata kuliah Wirausaha Kreatif di program studi Desain Komunikasi Visual (DKV) Fakultas Seni Rupa dan Desain Universitas Tarumanagara memilih metode Project Based Learning untuk perkuliahan semester genap 2020/ 2021 yang kemudian diangkat sebagai tema penelitidan dengan rumusan permasalahan i bagaimana penerapan project based learning pada mata kuliah wirausaha kreatif FSRD Untar. Penelitian yang dilakukan dapat menjadi contoh (model) bagi mata kuliah lainnya di program studi DKV Untar.

Penerapan PBL sudah banyak dilakukan di berbagai sekolah, mulai dari tingkat dasar, menengah, atas dan juga di perguruan tinggi. Berdarkan penelitian yang dilalkukan oleh Rina Febriana dari Universitas Negeri Jakarta PBL mempengaruhi perilaku sosial dan learning outcomes. Hasil penelitian mengindikasikan ada peningkatan perilaku sosial sebanyak $40.3 \%$ sedangkan peningkatan learning outcomes sebesar $7.67 \%$ dengan perbandingan kelas yang menggunakan metode biasa peningkatan sebanyak $4.67 \%$. Implikasi dari penerapan PBL bagi para siswa adalah peningkatkan aspek kognitif, afektif, dan psikomotorik (Febriana, 2017). Penerapan PBL pada bidang desain komunikasi visual juga pernah diteliti pada SMK Negeri 1 Sukasanda, Bali. Pada tahun 2017 dilakukan penelitian pada mata pelajaran videografi dengan hasil sangat positif. Pada tahun 2019 dilakukan penelitian PBL pada mata kuliah sketsa. Hasil penelitian menunjukan bahwa terdapat perbedaan prestasi belajar para siswa kelas X DKV yang belajar menggunakan media e learning moodle dan siswa yang belajar dengan menggunakan media power point. Respon para siswa dari penerapan e learning moodle sangat positif (Asititi, 2019). Penelitian tentang tata kelola pameran berbasis project based learning juga pernah dilakukan oleh Khamadi, Agus Setiawan, dan Dwi Puji Prabowo dari program studi Desain Komunikasi Visual Universitas Dia Nusawantoro. Berdasarkan penelitian yang dilakukan capaian pembelajaran dalam peningkatan kualitas dapat tercapai melalui metode project based learning (Khamadi, 2020).

Penerapan PBL pada pendidikan kewirusahaan juga pernah diteliti pada berbagai sekolah/ institusi pendidikan. Laily Fitria Wati meneliti tentang PBL berbasis potensi lokal pada mata pelajaran prakarya dan kewirusahaan di SMA/SMK, Malang. Peneliti mengembangkan model pembelajaran inovatif melalui metode PBL. Siswa diajak untuk membuat perencanaan proposal usaha produk olahan makanan dari bahan potensi lokal di Malang (Wati, 2019). Ada penelitian yang mengkaji penerapan model PBL dalam meningkatkan aktifitas dan hasil pembelajaran siswa pada mata pelajaran produk kreatif dan kewirausahaan. Hasil penelitian adalah setelah diterapkan model PBL siklus rata - rata keaktifan siswa pada pre-test adalah $2 \%$ kemudian meningkat menjadi $55,13 \%$ dan pada siklus I dan $75,56 \%$ pada siklus II. Rata - rata hasil belajar siklus I adalah $78,35 \%$ dan siklus II meningkat menjadi $88,39 \%$. Dapat disimpulkan bahwa model pembelajaran PBL dapat meningkatkan keaktifan dan hasil belajar siswa kelas XII, SMK Negari 1 Bogor (Khairat, 2020).

\section{METODE}

Desain penelitian ini adalah deskriptif kualitatif, menggunakan metode studi kasus melalui observasi, wawancara, artefak, dan intepretasi. Penelitian dilakukan di mata kuliah Wirausaha Kreatif, 
semester genap 2020/ 2021 program studi Desain Komunikasi Visual Universitas Tarumanagara. Observasi dan penelitian dilakukan secara daring pada bulan Januari - Juni 2021. Wawancara dilakukan dengan dosen wirausaha kreatif sebagai informan kunci. Pedoman wawancara berkenaan dengan penerapan PBL pada mata kuliah; mengapa dipilih PBL, bagaimana penerapannya, apa yang dihasilkan mahasiswa, dll. Artefak penelitian adalah Rencana Perkuliahan Semester (RPS) Wirausaha Kreatif dan tugas - tugas mahasiswa yang terbaik yang dipamerkan melalui media sosial. Prosedur penelitian dilakukan berdasarkan 4 tahapan, yaitu : Pendahuluan (persiapan, menggali infdormasi, merancang proses peruliahan), Pengembangan (pengumpulan informasi, pengembangan modul), Evaluasi (analisa data), Laporan Penelitian (pembuatan laporan, luaran dan publikasi ilmiah). Menggunakan analisa data kualiatif berdasarkan observasi, wawancara, dan intepretasi peneliti.

\section{HASIL DAN PEMBAHASAN}

Modul kewirausahaan telah diberikan oleh universitas kepada para dosen pengampu di berbagai program studi melalui kegiatan webinar dan briefing pengampu mata kuliah. Modul Kewirausahaan di bagi menjadi empat bagian, yaitu : (1) Mengenal Potensi Diri, (2) Inovasi dan Potensi Pasar, (3) Lean Canvas, (4) Bisnis Plan.

Berdasarkan modul tersebut kemudian tim pengajar di DKV Untar melakukan pengolahan dan pengembangan konten dengan menambahkan beberapa suplemen materi sebagai pengayaan, yaitu :

1. Materi pengenalan diri, trend bisnis abad 2021.

2. Materi Six Thinking Hat, dari buku Edward de Bono

3. Materi Lean Canvas diperkaya dengan beberapa variasi (Bisnis Model Canvas).

4. Kuliah Umum melibatkan dosen tamu dari alumni yang telah menjadi praktisi bisnis, yaitu John Alan dan Budianto Leoputra. Dilakukan 2 kali, sekali sebelum UTS dan sekali sesudah UTS.

Metode project based learning (PBL) dipilih untuk diterapkan dalam proses Pembelajaran dengan menimbang berbagai aspek. PBL atau pembelajaran berbasis proyek merupakan model pembelajaran yang berfokus melibatkan siswa dalam memecahkan masalah melaui pembuatan proyek. Pembelajaran berbasis proyek, instruksi difasilitasi oleh guru sebagai fasilitator dalam belajar, namun pada prosesnya dilakukan sendiri oleh siswa. Siswa menggali sendiri pengetahuannya melalui yang bersumber dari rasa keingintahuan alami mereka sendiri (Bell, 2010). Langkah pembelajaran berbasis proyek melatih pengembangan proses penelitian secara mandiri, menggali dan menghubungkan berbagai informasi, serta membuat keputusan dan penilaian atas berbagai hal yang ditemukan melalui proyek (Aldabbus, 2018). Pembelajaran berbasis proyek berpeluang menghasilkan pemahaman pembelajaran yang lebih dalam, kemampuan berpikir, dan meningkatkan motivasi belajar (Bell, 2010).

Proyek yang dikerjakan siswa dapat berupa proyek perseorangan atau kelompok dan dilaksanakan dalam jangka waktu tertentu, menghasilkan sebuah produk, yang kemudian ditampilkan atau dipresentasikan (Fathurrohman, 2015). Manfaat pembelajaran ini melatih diri siswa agar aktif dan mandiri dalam mengambil keputusan memilih topik tertentu yang sesuai dengan kemampuannya. Proyek yang dibuat perlu dirancang sesuai tujuan pembelajaran. Guru dapat menyesuaikan proyek dengan kebutuhan bahan ajar agar keterampilan yang digunakan dalam proyek sesuai dengan tujuan pembelajaran. Secara umum, langkah-langkah model pembelajaran berbasis proyek menurut ProjectBased Learning Handbook "Educationg the Millenial Learner" (2006) adalah sebagai berikut :
1. Essential Question
2. Plan
3. Schedule
4. Monitor
5. Assess
6. Evaluate 
Berdasarkan pengolahan oleh peneliti, pelaksanaan PBL di mata kuliah Wirausaha Kreatif disederhanakan menjadi 4 tahapan dengan penggabungan beberapa langkah untuk menyesuaikan dengan situasi dan kondisi perkuliahan, yaitu:

1. Briefing: pertanyaan pengarah (driving question), penjelasan projek. Selanjutnya mahasiswa dapat menentukan projek yang akan diambil, menentukan sumber daya, kegiatan dan jadual dalam menyelesaikan projek.

2. Monitoring: asistensi/ konsultasi. Dosen bertanya tentang progress dari projek yang dikerjakan. Mahasiswa dapat bertanya apabila ada kendala/ hambatan ataupun berkonsultasi terhadap proses pencarian data ataupun pembuatan projek.

3. Presentasi: seminar wirausaha kreatif. Mahasiswa membuat laporan projek dan mempresentasikannya dalam format PPT kepada kawan - kawan lainmnya di kelas, sehingga tercipta suasana saling berbagi dan belajar.

4. Evaluasi : penilaian projek melalui seminar dan pameran. Dosen melakukan penilaian berdasarkan proses sampai dengan presentasi dan diakhiri dengan karya pameran.

Mahasiswa diberikan pengetahuan dan ketrampilan tambahan untuk membantu mereka berdiskusi dan mencari ide Bersama melalui metode Six Thinking Hat dari Edward De Bono. Metode tersebut diberikan untuk membantu mahsiswa dalam mengembangkan critical thinking dan creativity. Mereka diharapkan mampu berpikir secara sistematis dan kreatif dalam memecahkan suatu permasalahan. Berdasarkan penelitian yang dilakukan metode tersebut mampu meningkatkan ketrampilan berbicara siswa dalam berdiskusi (Wulandari, 2017). Projek yang dikerjakan oleh mahasiswa dalam kelompok 3-5 orang adalah membuat bisnis model canvas (BMC) sampai menghasilkan proposal bisnis plan. Bisnis model canvas yang dibuat kemudian dipamerkan melalui media sosial program studi DKV. Bisnis model canvas dibuat dalam sebuah gambar-gambar ide sehingga setiap orang memiliki pemahaman yang sama dan riil terhadap tipe-tipe konsumen mereka, pengeluaran biaya, cara kerja perusahaan dan sebagainya. BMC diciptakan oleh entrepreneur asal Swiss, Alexander Osterwalder tahun 2005. Bisnis model canvas ini terdiri dari 9 pilar utama, yakni:

1. Customer Segment

2. Value Proposition

3. Channels

4. Customer Relationship

5. Revenue Streams

6. Key Activities

7. Key Resources

8. Key Partnerships

9. Cost Structures

Dalam visualisasinya, setiap elemen diwakilkan oleh sebuah kolom atau kotak. Inilah yang kemudian dikenal dengan template bisnis model canvas (Hasibuan, 2021) 


\section{UNTAR

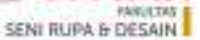

Mulyani Putri Sari / 625190094 Florencia Fora Santoso

Gladys Gozalie

Alfira Dwitania Ershano / / 625199102

\section{TERRAPY BUSINESS MODEL CANVAS WIRAUSAHA KREATIF}

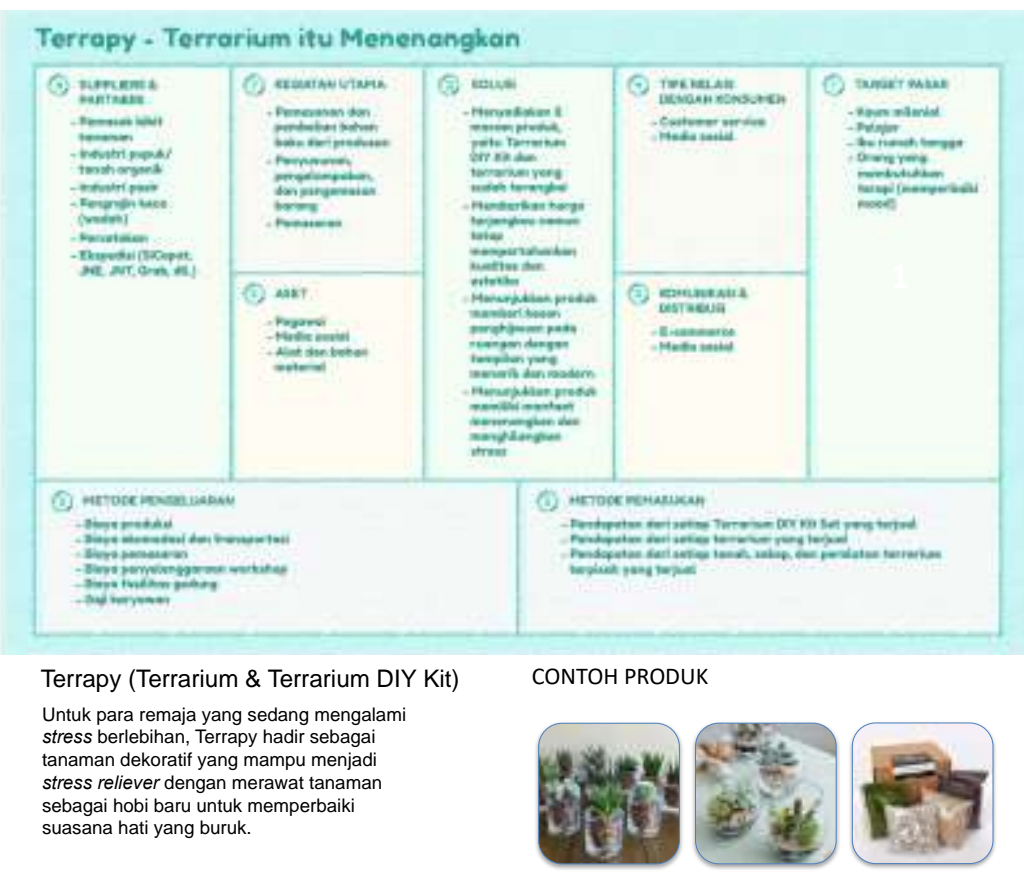

Gambar 1. Poster Bisnis Model Canvas "Terrapy"
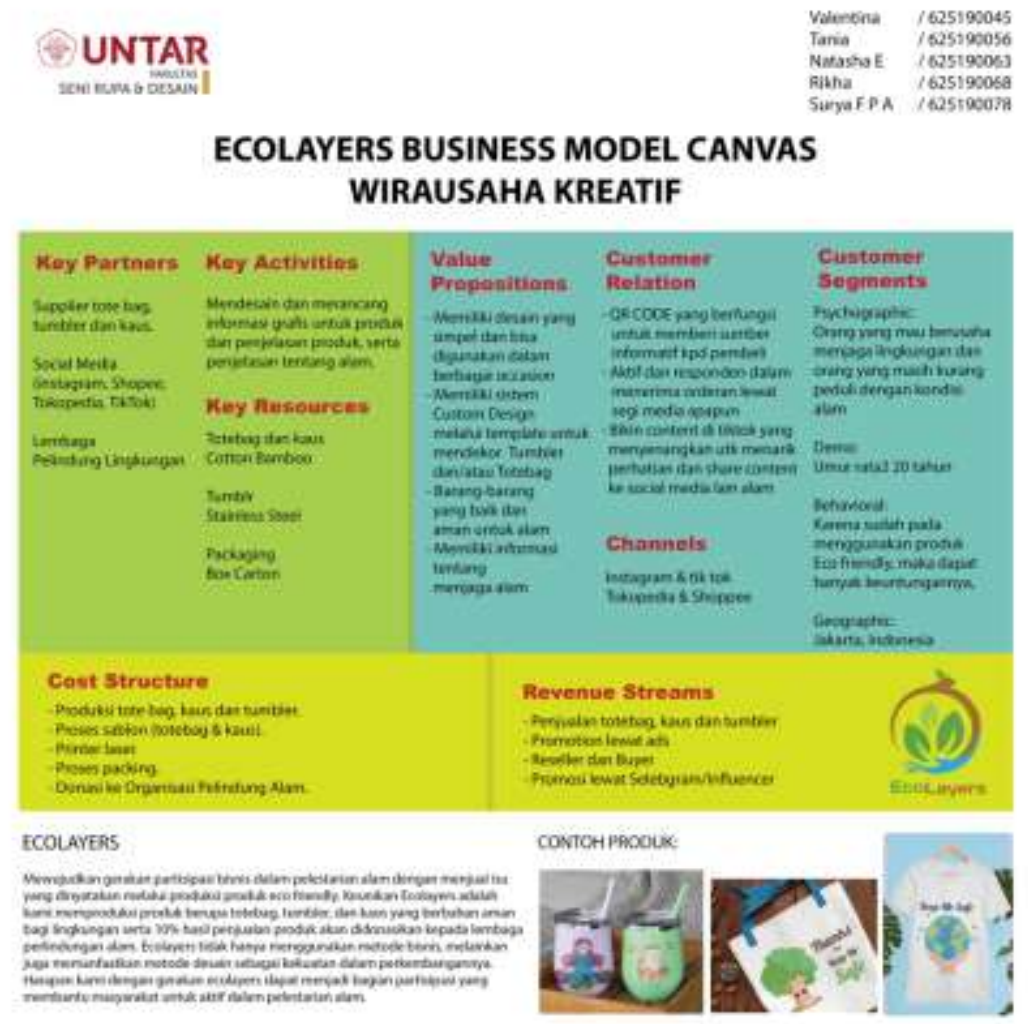

Gambar 2. Poster Bisnis Model Canvas "Eco Layer" 


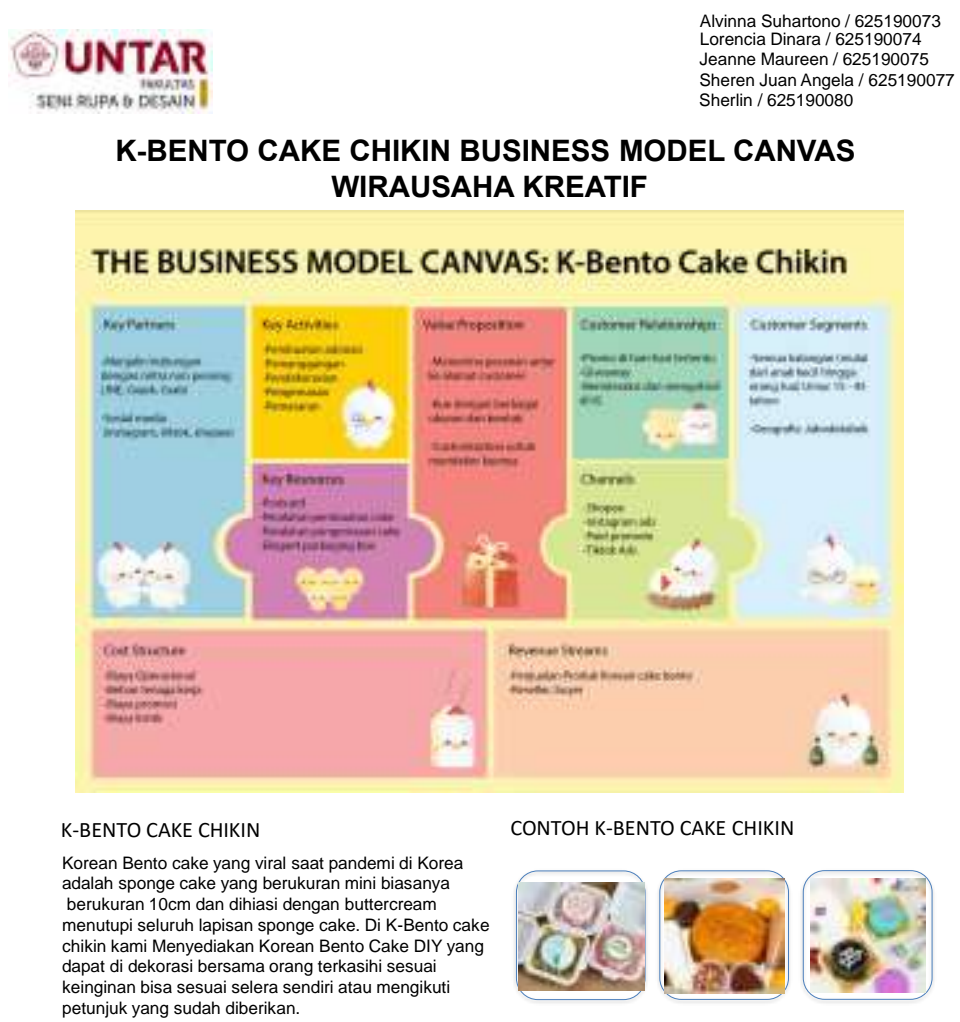

Gambar 2. Poster Bisnis Model Canvas "K-Bento Cake Chinkin"

Artefak yang dipilih ada 3 poster Bisnis Model Canvas yang terbaik sebagai contoh, yaitu : (1) Poster Terrapy. Mengembangkan fungsi tanaman dekoratif dengan nilai tambah sebagai stress reliever. Melalui merawat tanaman sebagai bagian dari aktivitas yang digemari untuk menciptakan suasana hati yang lebih tenang dan damai, (2) Poster Poster Ecolayer. Merchandise tote bag, kaus dan tumbler sebagai produk eco frienfly sekaligus menjadi bagian partisipasi membantu masyarakat terlibat aktif dalam pelestarian alam, (3) K-Bento Cake Chikin. Produk sponge cake yang berukuran mini berukuran $10 \mathrm{~cm}$ dihiasi dengan buttercream yang dapat di dekorasi sesuai keinginan bisa sesuai selera sendiri atau mengikuti petunjuk yang sudah diberikan.

Project based learning (PBL) di mata kuliah wirausaha kreatif prodi DKV diintegrasikan dengan RPS dan modul kewirausahaan. PBL diterapkan pada modul ke 3 dan 4 dari RPS yaitu saat para mahasiswa dibagi dalam kelompok dan membuat Bisnis Model Canvas dan Proposal Bisnis. PBL dilaksanakan dalam 4 tahapan, yaitu: (1) briefing, (2) monitoring, (3) presentasi, (4) evaluasi. Berdasarkan hasil observasi, dapat disimpulkan motivasi para mahasiswa ditumbuhkan melalui berbagai aktivitas dan materi, seperti menampilkan figur - figur wirausaha nasional dan internasional, tayangan video, studi kasus, dan memberikan pengetahuan tentang trend bisnis abad 21. Hal ini menjadi stimulan dan menambah minat belajar. Selanjutnya mahasiswa dapat terjun - praktik melakukan kajian tentang peluang bisnis melalui berbagai metode, seperti survey, wawancara, observasi, dll. Berdasarkan wawancara dengan dosen mata kuliah, penerapan PBL hasilnya luar biasa karena memunculkan beragam aneka bisnis yang menarik dan kreatif. Pada saat presentasi dalam seminar wirausaha kreatif ada beberapa temuan berkenaan dengan perbedaan tingkat kedalaman setiap kelompok dalam memahami permasalahan dan mereka dapat saling belajar dan memperkaya wawasan. Dalam hal ini kemampuan setiap siswa dan kelompok tidak sama. Tugas bisnis model canvas dan hasil akhir berupa proposal bisnis plan merupakan sintesa dari proses pembelajaran yang mereka ikuti selama satu semester. Hasil penelitian sejalan dengan beberapa penelitian tentang PBL seperti tertulis di pendahuluan, yaitu peningkatan kualitas pembelajaran (Khamadi, 2020), keaktifan siswa dan hasil belajar (Khairat, 2020). 


\section{SIMPULAN DAN SARAN}

Dapat disimpulkan metode project based learning sangat mendukung perkuliahan Wirausaha Kreatif sehingga dapat mencapai hasil yang baik. Proses perkuliahan menjadi lebih dinamis dan menarik bagi mahasiswa. Modul kewirausahaan diperkaya dengan beberapa suplemen tambahan, seperti Pengenalan diri (MBTI), Kuliah Umum dari praktisi, trend bisnis abad 21, metode Six Thinking Hat, dan Bisnis Model Canvas. Penerapan project based learning merupakan satu paket yang dapat dibagi dalam 4 tahapan yang saling berkesinambungan; briefing, monitoring, presentasi, evaluasi. Proses perkuliahan Wirausaha Kreatif berjalan lancar dengan menekankan pada "proses" belajar bagi mahasiswa sehingga pembelajaran menjadi milik mereka. Tugas dan Ujian berupa proposal bisnis plan dan poster bisnis model canvas menjadi wujud nyata hasil perkuliahan yang dapat bermanfaat bagi mahasiswa, fakultas dan juga dinikmati publik yang lebih luas dalam bentuk pameran di media sosial. Usulan dan saran berdasarkan penelitian yang dilakukan, metode project based learning direkomendasikan untuk diterapkan pada perkuliahan di FSRD dengan penyesuaian karakteristik masing - masing mata kuliah.

\section{ACKNOWLEDGEMENT}

Peneliti berterima kasih untuk dukungan dari Lembaga Penelitian dan Pengabdian kepada Masyarakat (LPPM) Universitas Tarumanagara, kepada tim dosen dan mahasiswa Wirausaha Kreatif DKV semester genap 2020/ 2021 yang turut berpartisipasi secara aktif sehingga penelitian ini dapat dilaksakan dengan baik.

\section{DAFTAR PUSTAKA}

Aldabbus, S. 2018. Project-Based learning: Implementation \& challenges. International Journal of Education, Learning and Development 6, no. 3, 71-79.

Astiti, Ni Nyoman Widya, Ketut Agustini, Gede Saindra Santyadiputra. 2019. Pengaruh E-Learning Moodle Berorientasi Project Based Learning terhadap Prestasi Belajar Siswa (Studi Kasus; Kelas X Desain Komunikasi Visual pada Mata Pelajaran Sketsa di SMK Negeri 1 Sukasanda). Kumpulan Artikel Mahasiswa Pendidikan Teknik Informatika (KARMAPATI) 8, no. 2, 172.

Bell, S. 2010. Project-Based Learning for the 21st century: Skills for the future. The Clearing House, 83, 39-43.

Drucker, Peter F. 1985. Innovation and Entrepreneurship; Practice and Principles. New York: Harper \& Row Publisher, 19.

Educational Technology Division, Ministry of Eductaion. 2006. Project-Based Learning Handbook "Eduacting the Millenial Learner". Kuala Lumpur: Communication and Training Sector Smart Educational Development Educational Technology Division, Ministry of Education, 22.

Fathurrohman, M. 2015. Model-model pembelajaran inovatif. Yogyakarta: Ar-Ruzz Media.

Febriana, Rina. 2017. The Effectiveness of Project Based Learning on Students' Social Attitude and Learning Outcomes, Jurnal Pendidikan Teknologi dan Kejuruan 23, no. 4 (Oktober), 374.

Hasibuan, Lynda Sari. 202021. Bisnis Model Canvas: Apa, Bagaimana Contohnya, www.cnbcindonesia.com/lifestyle

Khairat, Yaumil. 2020. Meningkatkan Aktifitas dan Hasil Belajar Peserta Didik pada Mata Pelajaran Produk Kreatif dan Kewirausahaan. Jurnal Teknologi Pendidikan 9,no.2 (Juli),185. 
Khamadi, Agus Setiawan, Dwi Puji Prabowo. 2020. Tata Kelola Pameran Berbasis Project Based Learning Program Studi Desain Komunikasi Visual Universitas Dian Nuswantoro. Journal of Art, Design, Education And Culture Studies (JADECS) 5, no. 1 (April), 30.

Moekijat. 1991. Evaluasi Pelatihan Dalam Rangka Peningkatan Produktivitas. Mandar Maju. Bandung.

Prianta, Komang, I Made Putrama, Dewa Gede Hendra Divayana. 2017. Pengembangan E-Modul Berbasis Model Pembelajaran Project Based Learning pada Mata Pelajaran Videografi untuk Siswa Kelas X Desain Komunikasi Visual di SMK Negeri 1 Sukasanda. Jurnal Nasional Pendidikan Teknik Informatika 6, no. 1 (Maret), 70.

Sukino, Charoline Dewi Virasari, Tipri Rose Kartika, dkk. 2021. Panduan Program Kewirausahaan Mahasiswa Indonesia 2021. Jakarta : Belmawa - Kemdikbud, 2.

Tyas, E. handayani. 2019. Menggapai Mimpi Melalui Entrepreneurship. Jakarta: UKI Press, 5.

Wati, Layla Fitria. 2018. Model Pembelajaran Project Based Learning Berbasis Potensi Lokal pada Mata Pelajaran Prakarya dan Kewirausahaan (SMA/SMK di Malang). Jurnal Teori dan Praksis Pembelajaran IPS 3, no. 1 (November), 39.

Wulandari, Ratna Rizky. 2017. Penerapan Metode Enam Topi Berpikir De Bono dalam Pembelajaran Berdiskusi (Kuasi Eksperimen pada Siswa Kelas XI SMK Negeri 13 Bandung Tahun Ajaran 2009/2010). LITERASI. Jurnal IImiah Pend. Bahasa, Sastra Indonesia dan Daerah 7, No.1 (Januari), 61. 